\title{
Un estudio contrastivo e interdisciplinar sobre la influencia emocional de los textos con carga emotiva negativa en los traductores
}

\section{A comparative and interdisciplinary study on the influence of emotionally negative triggering texts on translators}

\author{
LUISA MARÍA BATISTA ESPINOSA \\ luisabatistaespinosa@gmail.com \\ Universidad de Las Palmas de Gran Canaria \\ KONSTANTINA KONSTANTINIDI \\ nadia.konstantinidi@ulpgc.es \\ Universidad de Las Palmas de Gran Canaria \\ FRANCISCO JAVIER BATISTA ESPINOSA \\ fbatista@ull.edu.es \\ Universidad de La Laguna
}

Fecha de recepción: 10 de octubre de 2020

Fecha de aceptación: 20 de enero de 2021

Resumen: A menudo, los traductores se tienen que enfrentar a traducciones complejas a nivel emocional que pueden tener consecuencias tanto en el traductor como en el texto final. El objetivo del presente trabajo es analizar el grado de la influencia de los textos de carga emotiva negativa en el estado psicológico de los traductores, mediante la observación y la cuantificación de las emociones que experimentan antes, durante y después del proceso traductor, cuando lidian con este tipo de textos, comparando a traductores profesionales y en formación. Para ello, se ha utilizado el método de la verbalización del pensamiento en voz alta (TAPs) y la Escala de Valoración del Estado de Ánimo (EVEA), con el fin de obtener datos tanto cualitativos como cuantitativos, respectivamente. Los resultados indican que el estado de ánimo de todos los sujetos ha sufrido cambios tras la realización de la traducción. Además, a pesar de que existan variaciones cuantitativas entre los niveles emotivos de los dos grupos, las diferencias no son significativas. Por lo tanto, se puede concluir afirmando que, en mayor o en menor medida, los textos emotivos afectan a los traductores y que la profesionalidad puede que no sea uno de los factores relacionados con la gestión de las emociones en este tipo de textos.

Palabras clave: Traductor, Impacto emocional, Psicología, TAP, EVEA 
Abstract: Frequently, translators have to deal with emotionally complex translations that may have consequences on both the translator and the final text. The aim of this study is to analyse the degree of influence of those texts that trigger negative emotions, with which the translator should deal, through the observation and quantification of the emotions that they experience, before, during and after the translation process of this type of texts, by comparing professional and non-professional translators. For this purpose, the Thinking Aloud Protocols (TAP) and the EVEA have been used, in order to obtain data, both qualitative and quantitative, respectively. The results show that the psychological mood of all the subjects has changed after the translation process. Furthermore, although there are variations between the emotional levels of the two groups, the differences are not significant. It can therefore be concluded that emotional texts affect translators to a greater or lesser extent and that professionalism may not be one of the factors related to the management of emotions in this type of texts.

\section{Keywords: Translator, Emotional impact, Psychology, TAP, EVEA}

\section{INTRODUCCIÓN}

El estudio de la mente humana ha sido siempre uno de los mayores enigmas de la ciencia. Analizar el funcionamiento de la mente y cómo esta se comporta ante ciertas tareas ha suscitado el interés tanto de filósofos como de científicos, desde la antigüedad. La traducción, como actividad mental compleja, ha sido objeto de análisis desde la perspectiva de la Traductología, la Neurolingüística, la Psicolingüística y otras ciencias interdisciplinarias cognitivas, desde los años 80 . Sin embargo, no ha sido hasta hace aproximadamente veinte años cuando la Traducción realmente empezó a experimentar un gran desarrollo, sistematizando diferentes aspectos relacionados con la mente de los traductores, entre los que se encuentran las emociones y su influencia en el proceso traductor.

Las emociones son inherentes al ser humano, inciden en nuestra manera de pensar y se pueden estudiar y cuantificar a través de nuestra conducta. Por ende, no resulta extraño que se hayan relacionado con diferentes aspectos presentes en la tarea traductora. A pesar de que no son abundantes los estudios realizados sobre este ámbito, varios autores (Hubscher-Davidson, 2018; Lehr, 2013; Valero-Garcés, 2006; Hansen, 2005; Baistow, 2000; Loutan, Farinelli y Pampallona, 1999) han establecido las bases sobre las que emerge esta investigación y han destacado la problemática a la que se enfrentan los traductores, en relación con la traducción de textos de carga emotiva, la gestión de las emociones y las consecuencias que pueden conllevar a nivel emocional. El presente estudio experimental se ha realizado con el fin de resaltar la importancia de investigar 
la carga psicológica del traductor y la complejidad de la traducción desde el punto de vista psicoemocional.

El objetivo principal de este estudio consiste en corroborar el grado de la influencia emocional que algunos textos pueden ejercer sobre los traductores, cuantificando las emociones que experimentan antes de, durante y tras la realización de la traducción de textos con carga emotiva. Más concretamente, se pretende hacer una comparación del comportamiento y de los procesos metacognitivos entre los traductores profesionales y los no profesionales, con el fin de destacar las posibles semejanzas y diferencias entre ambos grupos. Por otra parte, debido al diseño del estudio, se pretende evaluar la idoneidad de la metodología utilizada, ya que se triangulan datos procedentes de diferentes métodos de investigación, entre ellos el método de verbalización del pensamiento en voz alta o Thinking Aloud Protocols (TAPs) y la Escala de Valoración del Estado de Ánimo (EVEA).

Con el presente estudio, tratamos de verificar las siguientes hipótesis:

- A los traductores profesionales no les afectará anímicamente el contenido del texto mientras realizan la traducción, ya que se estima que estarán familiarizados con este tipo de textos y, además, debido a su actividad profesional, se abstendrán de implicarse emocionalmente con el contenido.

- Al finalizar la traducción, los traductores no profesionales obtendrán una puntuación más alta en las subescalas de tristeza-depresión, ansiedad e ira-hostilidad de la EVEA.

- La triangulación de datos procedentes de los protocolos de verbalización del pensamiento (TAPS) y de la EVEA constituye una metodología adecuada para obtener datos acerca de la manera en la que los textos emotivos afectan emocionalmente a los traductores.

\section{LA INVESTIGACIÓN PSICOLÓGICA EN EL ÁMBITO DE LA TRADUCCIÓN}

Las investigaciones en Traductología hoy en día han cambiado de enfoque y se centran en los diferentes aspectos presentes en el proceso traductor. Dentro de este enfoque cognitivo y empírico, el interés también se centra en las características y diferencias individuales del traductor, sus actitudes, creencias, estrategias y procesos creativos, entre otros factores, ya que se considera que determinan el proceso de traducción en sí (Rodrigues, 2002, citado en Bolaños, 2015, p. 151). La mente del traductor, también denominada «caja negra» (Krings, 1986; Lörscher, 1991; Rabadán, 1992), gana protagonismo, y gran parte de las investigaciones se dedican a estudiar el espacio mental del traductor (Hurtado, 2011), centrándose en la figura del traductor y en su entorno social (Wolf y Fukari, 2007). Debido a que estas 
tendencias de investigación han estado en pleno auge en las últimas décadas, un nuevo ámbito interdisciplinar se está consolidando dentro de la Traductología cognitiva, la denominada «psicología de la traducción» (Holmes, 1972/1988; Bolaños, 2015).

Por su parte, Ladmiral (1996) resalta en su investigación tres áreas de la psicología necesarias para la psicología de la traducción: la psicología cognitiva para analizar la mente del traductor, la psicología social para analizar la influencia de los aspectos sociales del traductor y la psicología general. Así, según Jääskeläinen (2012, p. 191), esta subdisciplina se extiende «desde la cognición (percepción, memoria, aprendizaje, resolución de problemas) al efecto o la emoción (motivación, actitudes) y la personalidad» e incluye los estudios de recepción y los aspectos sociales del traductor y su entorno (Bolaños, 2015, p. 151).

Dentro de la psicología de la traducción, podemos encontrar diferentes perspectivas de investigación y diferentes aspectos sobre los que los autores pueden incidir (Bolaños, 2016, p. 67). En este sentido, realizaremos un especial acercamiento a la idea promulgada por Asadi y Séguinot (2005, citado en Bolaños, 2014, p. 200) que afirman que los procesos mentales de cada traductor son únicos y que es difícil sistematizarlos en categorías estancas. Por tanto, estamos ante la psicología de las diferencias individuales, que abarcan las diferentes actitudes, personalidades y disposiciones entre traductores (Hubscher-Davidson, 2018).

\subsection{Las diferencias individuales}

El creciente interés por investigar los procesos cognitivos del traductor pone de manifiesto la necesidad de analizar las características específicas y las diferencias individuales intragrupales, ya que la personalidad y la experiencia del traductor tendrá un impacto diferente (Saldanha y O'Brien, 2013). Por ese motivo, cada vez más autores pretenden analizarlas para tenerlas en cuenta en sus investigaciones.

Atendiendo a la definición de Sánchez-Elvira y Olmedo (2003, p. 107), la psicología de las diferencias individuales trata «la descripción, predicción y explicación de la variabilidad interindividual, intergrupal a intraindividual con respecto a su origen, manifestación y funcionamiento». Reiss (1971/2000) es el primer autor que menciona de manera explícita la importancia de la personalidad del traductor y de la influencia que esta tiene en la toma de decisiones y en el texto final. Además, siguiendo la distinción establecida por Spranger (1920) sobre los seis tipos básicos de personalidad (teórica, económica, estética, social, política y religiosa), afirma que, dependiendo del tipo de personalidad a la que pertenezca el traductor, este será más o menos adecuado para realizar ciertos tipos de traducciones. Por ejemplo, un 
individuo que se encuentra dentro del tipo estético puede estar más cómodo traduciendo textos expresivos, mientras que un individuo del tipo teórico puede estar más cómodo con textos económicos.

Desde entonces, cada vez más autores se han dado cuenta de la estrecha relación que existe entre la personalidad del individuo y la competencia traductora, y cómo esta influye en el resultado final de la traducción. Hubscher-Davidson (2007) demostró empíricamente la influencia que tiene la personalidad del traductor en su actitud, rendimiento y en la calidad del TM (citado en Bolaños, 2014, p. 202) y, además, afirma que puede tener tanto efectos positivos como negativos en la traducción (HubscherDavidson, 2018).

Bolaños (2014, p. 203) afirma que este nuevo interés sobre la personalidad y características individuales del traductor ha desembocado en nuevas investigaciones que, a pesar de que no se centran directamente en la personalidad del traductor, tienen otros objetivos relevantes para la psicología de las diferencias individuales y para la Traductología cognitiva. Entre ellas, destacamos la inteligencia emocional, ya que, aunque no se analice directamente en nuestro estudio, influye en la manera en la que los traductores regulan sus emociones.

\subsection{La inteligencia emocional en la traducción}

La inteligencia emocional (IE) hace referencia a la capacidad para reconocer, gestionar y regular emociones tanto en nosotros mismos como en los demás (Goleman, 1995) y se contempla como una de las dimensiones más importantes de la inteligencia (Murphy, 2006).

En muchas ocasiones los traductores se enfrentan a situaciones que les pueden afectar emocionalmente, y la manera en la que regulan estas emociones puede influir directamente sobre diferentes aspectos del proceso traductor (Hubscher-Davidson, 2018, p. 121). Por ese motivo, la investigación acerca de la inteligencia emocional de los traductores y de su influencia en diferentes aspectos de la traducción ha ganado protagonismo en los últimos años. Cada vez más investigaciones contemplan que la inteligencia emocional es necesaria para entender el proceso traductor (HubscherDavidson, 2013) y que los niveles de inteligencia emocional de un traductor pueden influir directamente en sus procesos mentales (Pahlavani y Asroush, 2013). Además, se relaciona con el aumento de la productividad (Lam y Kirby, 2002) y con el desempeño de tareas de manera exitosa (Schutte, 2001) y, por lo tanto, puede influir en la calidad final del texto meta (Varzande y Jadidi, 2015, p. 105). 


\subsection{Impacto psicológico y emocional en los traductores}

Como ya se ha señalado anteriormente, en la actualidad, las investigaciones en Traductología tienen finalidades muy diversas y gran parte de estos estudios se dirige a analizar el producto final del proceso traductor (Basile, 2005, p. 13). Sin embargo, son más escasas las investigaciones dedicadas al análisis de conceptos de índole psicoemocional, como el impacto psicológico y emocional de los traductores o el compromiso afectivo de los traductores con el texto origen, como también, la influencia emocional del proceso traductor.

Las investigaciones sobre el impacto emocional y psicológico de los traductores e intérpretes se han llevado a cabo centrándose, mayoritariamente, en los servicios públicos y en el ámbito sanitario, debido a que en estas especializaciones son más comunes las situaciones críticas, los acontecimientos estresantes y el tratamiento de temas complicados. Por tanto, el traductor/intérprete no se limita al mero traslado de información (Valero-Garcés, 2006), sino que se involucra emocionalmente. Loutan, Farinelli y Pampallona (1999, p. 280) resaltan la importancia de investigar sobre el impacto emocional de la interpretación, cuando el profesional tiene que lidiar con situaciones de carga emocional negativa, como dolor, muerte y luto.

En su investigación, Valero-Garcés (2006) recoge las principales consecuencias que conlleva trabajar en contextos con un impacto emocional alto y clasifica las consecuencias en tres tipos: profesional, laboral y extralaboral. A nivel profesional, destaca la ansiedad, el estrés, la pérdida de memoria, la fatiga profesional (también conocida como síndrome burnout), el fenómeno transferencia-contratransferencia y el llamado «trauma vicario» (Blair y Ramones, 1996, p. 24). A nivel laboral, puede observarse absentismo, una menor implicación profesional o deterioro de la calidad de trabajo, mientras que, a nivel extralaboral, pueden surgir problemas familiares y aislamiento, entre otros.

Además, expertos como Baistow (2000) y Clark y Gioro (1998) afirman que el manejo de estas situaciones críticas puede verse influenciado negativamente por tres variables principales que hay que tener en cuenta al hablar del impacto psicológico en traductores e intérpretes: variables personales, situacionales y contextuales, como son la proximidad a la fuente del trauma, la posible relación con pérdidas personales, la falta de apoyo en el entorno social o atravesar momentos de fuerte impacto vital como divorcios, depresiones y enfermedades de seres queridos. Además, estas situaciones suelen ir acompañadas de síntomas a nivel fisiológico, cognitivo $\mathrm{y}$ afectivo que pueden afectar negativamente en el resultado final de una 
traducción, adoptando la forma de fatiga, conducta antisocial, incapacidad de descansar, disminución para razonar, falta de concentración, tristeza, irritabilidad o ansiedad.

Por otra parte, según Valero-Garcés (2006, p. 143), el tipo de usuarios a los que los traductores e intérpretes prestan su servicio también puede provocar empatía (Hubscher-Davidson, 2018) y, por consiguiente, estrés psicológico en el traductor, especialmente, usuarios con los que el traductor puede compartir ciertas experiencias, que han experimentado situaciones de violencia, pérdidas de seres queridos o con un estado emocional deteriorado. Rojo y Ramos (2016, p. 107) explican que las emociones son esenciales en los seres humanos e influyen directamente en la manera en la que aprendemos y trabajamos. Por ese motivo, la gestión de las emociones juega un papel fundamental en estas situaciones complicadas con las que tienen que lidiar constantemente traductores e intérpretes.

Sin embargo, la mayor parte de los estudios que analizan las emociones se centran en la manera en la que se traducen estos contenidos y no en cómo afectan este tipo de textos a los traductores (HubscherDavidson, 2013), pero cada vez más autores enfatizan la importancia de investigar el modo en el que los traductores gestionan las emociones y la manera en la que estas influyen en el producto final de su trabajo (Anderson, 2005, p. 179). Además, según Rojo (2015, p. 739), investigar las emociones en traducción puede arrojar luz sobre otros aspectos, como procesos comunicativos o de toma de decisiones.

Según Hubscher-Davidson (2018, p. 33), los estudios empíricos han demostrado que las características emocionales del traductor pueden influir en la manera en la que perciben los contenidos del texto origen, en la calidad del texto meta y en cómo los lectores reciben el texto traducido. Además, afirma que esas características emocionales y afectivas del traductor pueden, en ocasiones, influir más en las traducciones que en las propias habilidades lingüísticas del traductor. Por su parte, Hansen (2005, p. 516) subraya que, en determinadas ocasiones, esas emociones son inconscientes e incontrolables y, por lo tanto, su influencia en el proceso traductor es aún mayor.

Más concretamente, diversos estudios muestran que no solo las emociones negativas influyen en la toma de decisiones durante el proceso traductor, sino que también las emociones positivas tienen un impacto en los traductores. La manera en la que los traductores perciben, regulan y traducen las emociones influye tanto a los traductores como al texto meta y no solo a efectos negativos (Bush, 2012, p. 122). Además, Lehr (2013) y Davou (2007) consideran que las emociones positivas aumentan la creatividad, mientras 
que las negativas fomentan la precisión en la traducción de terminología. Conforme a esto, se puede concluir afirmando que las emociones son una parte integral de la traducción y que, normalmente, el estudio de las emociones está estrechamente relacionado con las diferencias individuales y la inteligencia emocional de cada traductor.

\section{LA INVESTIGACIÓN EXPERIMENTAL EN LA TRADUCTOLOGÍA}

Dentro de las investigaciones empíricas en el ámbito de la Traductología podemos encontrar diferentes objetivos, herramientas de recopilación de datos y métodos de investigación, pero para que un estudio se considere empírico-experimental, debe cumplir con una serie de criterios de exactitud experimental (Neunzig, 2001). Entre los principales criterios se registran la objetividad del investigador, la replicabilidad o reproducibilidad del estudio, la generalización o extrapolabilidad, la fiabilidad, la validez, la cuantificabilidad y la validez ecológica o situacional (Soto Almela, 2015). El cumplimiento con estos criterios no siempre es fácil en Traductología y, por eso, en general, en las investigaciones sobre la metodología empírica las opiniones de los autores son muy diversas, respecto a la multidisciplinariedad y los instrumentos utilizados.

La investigación empírica en el ámbito de la Traductología cuenta con una escasez de instrumentos de medida y de recopilación de datos propios. Contamos con herramientas que se han creado específicamente para investigaciones en Traductología, como Translog o Proxy, pero estas herramientas son escasas y se centran en aspectos concretos de investigación. Esto ha llevado a que los investigadores tengan la necesidad de utilizar instrumentos propios de otras disciplinas, como las Ciencias de la Educación, la Psicología o la Lingüística. (Neunzig, 2001). En la actualidad el uso de estas herramientas «importadas» de otras disciplinas, los llamados «instrumentos foráneos», está bastante extendido en Traductología. Dentro de estos podemos encontrar entrevistas exploratorias, retrospección o entrevistas inmediatas, encuestas, tests, cuestionarios, protocolos de pensamiento en voz alta, pruebas psicométricas, herramientas procedentes de la psicología cognitiva como el lector de movimientos oculares (eyetracker), etc.

A continuación, nos centraremos en dos instrumentos foráneos que han constituido la base de nuestro estudio: los protocolos de pensamiento en voz alta (Thinking Aloud Protocols o TAPS), que se engloban dentro de los métodos introspectivos, y las pruebas psicométricas, que nos ayudarán cuantificar los datos recogidos del experimento. 


\subsection{LOS TAPS}

Los «protocolos de pensamiento en voz alta», también conocidos como «protocolos de verbalización del pensamiento o protocolos del pensamiento manifestado", son instrumentos metodológicos en los que el sujeto verbaliza sus pensamientos, sensaciones u opiniones mientras lleva a cabo una actividad. Ericsson y Simon (1980) presentaron este modelo con la finalidad de resaltar la importancia de la introspección. Una de sus principales conclusiones fue que las personas, mediante los relatos verbales de sus pensamientos, pueden proporcionar información válida sobre los productos de su procesamiento, más que sobre los procesos en sí mismos.

Los TAPs se han utilizado comúnmente en estudios de psicología cognitiva en actividades de resolución de problemas, y su uso se extendió a la traducción coincidiendo con las investigaciones sobre el proceso traductor y sobre lo que ocurre en la mente de los traductores. En los años 80 , se utilizó por primera vez esta metodología en un estudio sobre traducción escrita (Sandrock, 1982; Krings, 1986), en el que se les solicita a los sujetos del estudio que, mientras traducen, verbalicen los pensamientos e ideas que les van surgiendo. Estas verbalizaciones se graban y se transcriben en protocolos para su análisis posterior. A partir de estas primeras investigaciones, este método se ha estado utilizando con la finalidad de proporcionar datos empíricos sobre la traducción (Bell, 1998; Jääskeläinen, 1998; Presas, 1996). Muestra de ello, son las más de cincuenta investigaciones que recoge Orozco-Jutorán (2002), que se han llevado a cabo mediante este método. Además, tal y como muestran Ferreira, Schwieter y Gile (2015) el uso de los TAPs fue la primera contribución visible de la psicología en la investigación sobre la traducción escrita.

Ericsson y Simon (1993) organizan los informes orales en tres niveles en relación con lo que el procedimiento requiere de los informantes. Un informe oral se considera de nivel 1 cuando no se requiere ningún esfuerzo del sujeto, de nivel 2 cuando no afecta directamente al proceso cognitivo, pero sí ralentizan la ejecución de la tarea, y de nivel 3 cuando se requiere control consciente de los informantes, es decir, se ve afectado el desarrollo y la estructura del proceso cognitivo. Por lo tanto, los protocolos de verbalización del pensamiento producen informes del nivel 2.

Los protocolos de pensamiento en voz alta mayoritariamente son simultáneos, en los que el traductor va explicando lo que sucede en su mente a la vez que va traduciendo, aunque en algunas ocasiones también se han utilizado TAPs retrospectivos (Mondhal y Jensen, 1992; Fraser, 1993; etc.), en los que el traductor realiza los comentarios una vez haya finalizado la traducción. A su vez, los TAPs se pueden realizar con un solo sujeto de 
estudio o con varios, pueden ser dialogados (Kussmaul, 1995) en los que el traductor interactúa con el investigador, o en la mayor parte de los casos sin ningún tipo de interacción. Asimismo, los sujetos pueden ser grabados en vídeo y en audio o solamente en audio. Jääskeläinen (1998) afirma que los TAPs permiten una mejor comprensión de los mecanismos psicológicos y lingüísticos implicados en el acto de traducir, ya que pueden proporcionar datos válidos sobre las estrategias de toma de decisiones, la resolución de problemas y otras actividades de carácter cognitivo (Lörscher, 1991; Jensen, 1999; etc.).

Asimismo, se ha destacado la necesidad de combinarlo con otras herramientas de recopilación de datos (Orozco, 2002). Así pues, numerosos autores han optado por una perspectiva multimetodológica, combinando los TAPs con otros métodos de investigación, como los cuestionarios (Krings, 1986; Alves, 1996; etc.), la observación directa, las mediciones a través del ordenador (Lorenzo, 1999; Hansen, 1999; etc.) o las entrevistas posteriores, entre otros.

\subsection{Los instrumentos de evaluación psicológica}

Los instrumentos de evaluación psicológica es la herramienta foránea más antigua utilizada en el ámbito de las investigaciones traductológicas y se considera que sirven de gran ayuda a la hora de proporcionar datos sobre diferentes aspectos de las traducciones de manera fácil y rápida, especialmente para obtener datos sobre los procesos mentales del traductor. Además, según Bolaños (2014), son muy útiles en los estudios sobre las diferencias individuales de los traductores.

Un elemento de gran importancia en toda investigación empírica es la correcta elección de los métodos utilizados. En el caso de las pruebas psicométricas, al tratarse de un elemento foráneo, se debe tener claro el objetivo principal del estudio y las características particulares que recoge cada tipo de prueba, con la finalidad de que nos aporte los datos necesarios. Así, Bolaños (2012, p. 471) afirma que, dentro de los instrumentos de evaluación psicológica, podemos encontrar numerosos tipos -autoinformes, observación, técnicas subjetivas, técnicas proyectivas y técnicas objetivas (Moreno Rosset, 2005, p. 93) - y cada uno posee unas peculiaridades y características propias, lo que lo hacen más o menos adecuado para cada tipo de investigación. En este trabajo, en concreto, se utiliza una escala, en forma de autoinforme, que sirve para medir el grado en el que el individuo está de acuerdo o en desacuerdo con su contenido. Este tipo de informes suelen utilizarse, entre otras situaciones, en la valoración de los aspectos motivacionales (Bolaños, 2012, p. 471). En concreto, se ha seleccionado la Escala de Valoración del Estado de Ánimo (EVEA), tanto por su capacidad 
para detectar cambios en estados de ánimo, como también por la facilidad que presenta su administración.

\subsection{La Escala de Valoración del Estado de Ánimo (EVEA)}

La Escala de Valoración del Estado de Ánimo (EVEA) es un inventario de autoinforme de lápiz y papel que se utiliza para medir el estado de ánimo del sujeto. La EVEA se construyó como un instrumento «para medir estados de ánimos transitorios en los estudios que utilizan procedimientos de inducción de estado de ánimo (PIEAs)» (Sanz, 2001, p. 71), pero también se puede utilizar en cualquier circunstancia en la que se quiera medir el estado de ánimo transitorio de una persona en un momento dado. Esta escala tiene como objetivo principal detectar posibles cambios que se puedan producir en esos estados de ánimo, debido a factores ambientales o contextuales, y el tiempo de administración estimado es de 1-2 minutos.

La EVEA consiste en una escala situacional formada por 16 ítems, cada uno compuesto por una escala gráfica de tipo Likert de 11 puntos (de 0 a 10), flanqueadas por las palabras «nada» (0) y «mucho» (10) y acompañada de una corta afirmación que siempre responde a la misma estructura. Cada afirmación empieza con las palabras «me siento» y continúa con un adjetivo que describe un estado de ánimo (p.ej., "me siento triste», «me siento alegre»). Los 16 ítems se agrupan en grupos de cuatro, formando a su vez cuatro subescalas, que corresponden a cuatro estados de ánimo generales: ansiedad, ira-hostilidad, depresión-tristeza y alegría.

La EVEA se trata de un instrumento de evaluación psicológica también conocido como «listas de adjetivos». Este tipo de instrumentos se adapta muy bien a las necesidades de la evaluación de los estados de ánimo y proporcionan información descriptiva mediante un sistema de respuestas muy sencillo, fiable en su procedimiento de recogida de datos y que requiere muy poco tiempo para su utilización (Ávila y Giménez, 1991). Por lo tanto, las listas de adjetivos es el procedimiento de evaluación del estado de ánimo más utilizado y, probablemente, el más adecuado (Pueyo, 1993) para el tipo de investigación que hemos diseñado.

Los resultados se pueden analizar de dos maneras. La manera más habitual es sumar la puntuación obtenida de los cuatro adjetivos que corresponden a cada subescala y dividir el resultado entre 4. Así, se obtendrán cuatro puntuaciones que oscilan entre 0 y 10 y que reflejan los estados de ánimo triste-depresivo, ansioso, alegre y hostil del sujeto en el momento en el que se administra el instrumento. Sin embargo, algunos investigadores optan por no dividir la suma de cada subescala y obtienen, por lo tanto, una puntuación que oscila entre 0 y 40 (Arjona Arcas, 2002; Hervas y Vázquez, 2013). Para la obtención del estado tristeza-depresión habría que 
sumar las puntuaciones de los ítems 4 «melancólico», 7 «alicaído», 10 «apagado», 16 «triste»; para el estado de ansiedad sumaríamos las puntuaciones de los ítems 1 «nervioso», 5 «tenso», 9 «ansioso», 13 «intranquilo»; para la subescala de ira-hostilidad habría que sumar las puntuaciones de los ítems 2 «irritado», 8 «enojado», 11 «molesto» y 14 «enfadado», $y$, por último, para el estado de alegría habría que sumar las puntuaciones de los ítems 3 «alegre», 6 «optimista», 12 «jovial», y 15 "contento». El orden de colocación de los ítems en la escala se realizó de manera aleatoria, pero evitando que dos ítems de una misma subescala aparecieran de forma consecutiva. La EVEA se puede aplicar antes y después de llevar a cabo una tarea cognitiva (Sanz y Dobson, 1994), únicamente antes o únicamente después (Sanz, 1994).

Según indica Sanz (2001), los adjetivos utilizados en la escala para medir los estados de ánimo "depresivo» y "alegre» se sacaron de las versiones en español de las Listas de Adjetivos para la Depresión (DACL, Depression Adjetive CheckList, Lubin, 1965) y los adjetivos para medir la ansiedad provienen de la escala de estado del State Trait Anxiety Inventory (STAl; Spielberger, Gorsuch y Lushene, 1970). Para la «hostilidad», los ítems se extrajeron de una traducción de la Escala de Ira Estado-Rasgo (STAS, Strate-Traig Anger Scale, Spielberger, Russel y Crane, 1983). A excepción del último, todos los instrumentos nombrados anteriormente que se utilizaron para sacar los adjetivos utilizados en la escala son adecuados y válidos. Además, tanto los autoinformes de ansiedad y de ira del grupo de investigación de Spielberger y la $D A C L$ de Lubin, tienen sus versiones originales anglosajonas muy avaladas por sus propiedades psicométricas y su frecuente uso como medidas de estados emocionales (Gotlib y Cane, 1989).

Existen numerosos estudios que demuestran la fiabilidad de la EVEA. Una revisión realizada por Sanz, Gutiérrez y García-Vera (2013) ha mostrado dicha fiabilidad teniendo en cuenta muestras que oscilaban entre 542 y 1269 participantes, llegando a coeficientes de «fiabilidad de consistencia interna» con una media de 0,88 para la subescala de tristeza-depresión, de 0,92 para la subescala de ansiedad, de 0,93 para la subescala de ira-hostilidad y de 0,92 para la subescala de alegría. Además, la «validez de criterio» se ha contrastado en cuatro estudios (Pacheco-Unguetti et al., 2011; Provencio Ortega, 2012; Romero Martín, 2012), mostrando que, por ejemplo, los pacientes con trastornos depresivos puntúan más bajo en la subescala de alegría y más alto en la subescala de depresión. Otro estudio, realizado en la Universidad de La Laguna con una muestra de 140 participantes, afirma que «la escala EVEA muestra una estructura factorial robusta, obteniéndose una 
conformación de acuerdo con las cuatro variables previstas» (Pino-Sedeño, Peñate y Bethencourt, 2010, p. 30).

Asimismo, es importante destacar para nuestro estudio, que las subescalas de la EVEA han demostrado una gran sensibilidad al cambio tras la aplicación de PIEAs dirigidos a inducir ansiedad, tristeza-depresión o alegría (p.ej. música, recuerdo autobiográfico, vídeo, imaginación guiada o imágenes). Las subescalas de los estados de ánimo negativos (tristezadepresión, ansiedad e ira-hostilidad) se han mostrado especialmente sensibles y los cambios han sido mayores en la subescala relacionada con el estado de ánimo que se pretendía inducir (Sanz, Gutiérrez y García-Vera, 2013).

A lo largo de este capítulo hemos realizado una revisión de la literatura de diversos campos que están directamente implicados en la presente investigación y que nos llevan directamente al análisis de las hipótesis de nuestro estudio. En el siguiente capítulo, nos dedicaremos a la presentación de nuestro experimento sobre la gestión de los textos con carga emocional por parte del traductor. En primer lugar, describiremos la metodología para, más adelante, presentar y explicar la investigación realizada. Finalmente, expondremos y analizaremos los resultados y las conclusiones obtenidas.

\section{Metodología}

El estudio ha seguido una doble metodología, con el fin de poder generar resultados válidos, ya que la variable dependiente (impacto emocional) es un constructo, que debía cuantificarse para ser medible y analizable.

Por un lado, mediante la utilización de los TAPs, se empleó el método de investigación cualitativa, de observación participante implicada y de aproximación ideográfica y émica, ya que el estudio trata de la percepción racional y emocional subjetiva de los participantes. Para registrar las conductas y las verbalizaciones manifestadas por los sujetos, usamos transcripciones -documentos de carácter personal y privado- que respaldamos con autoinformes, antes y después de los TAPs, como producto de la autoobservación.

Por otro lado, también se siguió el método de investigación cuantitativa, con el uso de la EVEA -mediante la cual hemos operativizado la variable dependiente-, de metodología cuasiexperimental pre-post, con un grupo cuasi control, para contrastar los resultados. 


\subsection{El pre-experimento}

Antes de realizar las pruebas a los seis sujetos que participaron en el estudio, se realizaron dos pruebas previas a dos sujetos, para comprobar la adecuación del diseño del experimento, controlar el uso de las herramientas y detectar cualquier posible inconveniente que pudiese surgir durante las pruebas formales. Gracias a la realización de las dos pruebas previas se pudieron detectar diferentes situaciones que hubieran influido negativamente el desarrollo de la investigación.

En primer lugar, se llegó a la conclusión de que la grabación del dispositivo con el que se pretendía grabar a los sujetos era de mala calidad, por lo que se tuvo que cambiar. En segundo lugar, para que los sujetos no se dieran cuenta que estaban siendo grabados, el dispositivo se colocó lejos y el sonido no se grababa correctamente. Por otra parte, durante el preexperimento, al pasar el segundo test EVEA al final de la sesión, los sujetos podían ver la copia que habían cumplimentado al principio y así, se observó que rellenaban el segundo test comparándolo con las emociones que habían elegido al principio, lo que tergiversaba los resultados. Además, se detectó que si la investigadora se colocaba al lado de los sujetos mientras traducían estos se podían sentir incómodos, y, por tanto, en las pruebas del experimento, nos colocamos a cierta distancia de los sujetos, para evitar sesgos provocados por la presencia del investigador.

\subsection{Los sujetos}

En la investigación participaron seis sujetos, que se clasificaron en dos grupos: tres sujetos profesionales (SP) y tres no profesionales (SnP). El grupo de SP estaba formado por dos mujeres y un hombre, todos profesores de la Universidad de Las Palmas de Gran Canaria, de edades comprendidas entre los 30 y los 42 años. El tiempo medio de experiencia de los SP son 14 años. Uno de los sujetos profesionales (SP3) se ha especializado en la traducción jurídica, mientras que los otros dos sujetos trabajan con traducciones de diferentes ámbitos, sin tener una especialización concreta.

El grupo de los SnP contaba con tres estudiantes que se encuentran en el último curso del grado en Traducción e Interpretación de la misma universidad, todos de 21 años y, al igual que el otro grupo, estaba formado por dos mujeres y un hombre.

\subsection{Los instrumentos}

Con el fin de obtener datos fiables y de validez ecológica, tanto cuantitativos como cualitativos, triangulamos datos procedentes de diferentes métodos de investigación: el método de verbalización del pensamiento en voz 
alta (TAPs), la escala de valoración del estado de ánimo (EVEA) y un cuestionario personal compuesto de nueve preguntas para obtener más información de cada sujeto. Además, se utilizó el programa estadístico SPSS, comúnmente utilizado en las ciencias sociales y aplicadas, para analizar si las medias obtenidas en la EVEA son estadísticamente válidas.

\subsection{El texto}

El texto original que proporcionamos a los sujetos para su traducción al español tenía que cumplir con tres requisitos: brevedad, emotividad y cierto grado de dificultad. A este respecto, se eligió una parte del artículo de Meridith Kohut e Isayen Herrera, publicado el 17 de diciembre 2017 en el periódico The New York Times, que narraba la historia real de la muerte de un bebé en Venezuela, debido a la crisis con la que se enfrenta el país desde 2015, en relación con la escasez de alimentos y la malnutrición de los niños. La parte del artículo seleccionada constaba de 255 palabras, ya que se pretendía que el texto fuera relativamente corto, para prevenir y evitar estados de cansancio - aburrimiento por parte de los sujetos, que podrían repercutir en los resultados del estudio. Además, añadimos cuatro imágenes incluidas en el artículo original, con el fin de aumentar la emotividad del texto de manera visual.

\subsection{El procedimiento}

Las pruebas se desarrollaron entre febrero y marzo de 2019, con una duración media de una hora y los seis sujetos colaboraron conforme a los requisitos del estudio en su tiempo libre. Cabe mencionar que el objetivo principal del estudio no se les comunicó hasta la finalización de cada sesión. Las sesiones se realizaron de manera presencial e individual, excepto una que se realizó por videoconferencia, debido a la imposibilidad de uno de los SP de llevarla a cabo presencialmente.

Al comenzar cada sesión, se entregaba al sujeto una copia de la EVEA, que debían cumplimentar y, posteriormente, se les proporcionaban todas las instrucciones relevantes para la realización de la tarea. Las instrucciones incluían información detallada sobre el skopos de la traducción (periódico de publicación, tipo de lectores, etc.), el libre acceso a Internet durante la prueba, el tiempo ilimitado de que disponían, la obligación de verbalizar en voz alta cualquier idea y pensamiento que se les ocurría mientras duraba el proceso de traducción y, al final, se aseguraba la anonimidad de su participación.

Con el fin de comprobar la adecuación de los TAPs y poder observar a los sujetos en un ambiente natural para evitar sesgos, no se les comunicó previamente que estaban siendo grabados durante toda la prueba. Así pues, los sujetos comenzaban a traducir mientras se grababa la sesión únicamente 
en audio, ya que se consideró innecesaria la grabación en video, ya que esta infringía la normativa de ética del investigador sin el consentimiento previo de los participantes.

Tras la finalización de la traducción, los sujetos tendían que cumplimentar otra copia de la escala EVEA pre-post. Al final de cada sesión, informamos a todos los sujetos sobre la metodología que empleamos y la finalidad del estudio, y además, les informamos de que estaban siendo grabados durante toda la sesión, pero que tenían la total libertad para decidir si autorizaban a las investigadoras a utilizar los datos procedentes de las grabaciones o si, por el contrario, preferían renunciar formalmente a que los datos de los audios formasen parte del estudio, recordándoles que se mantendría el anonimato y que toda la información recopilada estaba sujeta a fines de investigación. Todos los sujetos autorizaron el uso de las grabaciones, mediante un consentimiento informado por escrito. Finalmente, les dirigimos una serie de preguntas, recogidas a modo de cuestionario, para obtener datos cualitativos complementarios a la información recopilada.

\section{Resultados}

En primer lugar, expondremos los datos obtenidos por grupos de sujetos, comenzaremos con los SP, y a continuación, analizaremos los resultados de los SnP. Finalmente, realizaremos una comparación entre los dos grupos.

\subsection{Sujetos profesionales (SP)}

\subsubsection{Datos cuantitativos (EVEA)}

Comenzaremos exponiendo los datos cuantitativos procedentes de la EVEA. No se analizarán los resultados obtenidos de cada ítem, sino que examinaremos los resultados por subescalas, sumando los resultados de los cuatro ítems que conforman cada subescala. Por lo tanto, se obtendrán resultados que oscilan entre 0 y 40 , siendo 40 la puntuación más alta posible para cada subescala.

\begin{tabular}{|l|l|l|l|l|l|}
\hline \multicolumn{2}{|c|}{ SP1 } & \multicolumn{2}{c|}{ SP2 } & \multicolumn{2}{c|}{ SP3 } \\
\hline PRE & POST & PRE & POST & PRE & POST \\
\hline 0 & 27 & 0 & 16 & 7 & 2 \\
\hline
\end{tabular}

Tabla 1: Resultados de la subescala de «tristeza-depresión» de los SP 


\begin{tabular}{|l|l|l|l|l|l|}
\hline \multicolumn{2}{|c|}{ SP1 } & \multicolumn{2}{c|}{ SP2 } & \multicolumn{2}{c|}{ SP3 } \\
\hline PRE & POST & PRE & POST & PRE & POST \\
\hline 4 & 13 & 0 & 25 & 1 & 0 \\
\hline
\end{tabular}

Tabla 2: Resultados de la subescala de «ansiedad» de los SP

\begin{tabular}{|l|l|l|l|l|l|}
\hline \multicolumn{2}{|c|}{ SP1 } & \multicolumn{2}{c|}{ SP2 } & \multicolumn{2}{c|}{ SP3 } \\
\hline PRE & POST & PRE & POST & PRE & POST \\
\hline 0 & 27 & 0 & 35 & 1 & 0 \\
\hline
\end{tabular}

Tabla 3: Resultados de la subescala de «ira-hostilidad» de los SP

\begin{tabular}{|l|l|l|l|l|l|}
\hline \multicolumn{2}{|c|}{ SP1 } & \multicolumn{2}{c|}{ SP2 } & \multicolumn{2}{c|}{ SP3 } \\
\hline PRE & POST & PRE & POST & PRE & POST \\
\hline 32 & 16 & 32 & 0 & 14 & 25 \\
\hline
\end{tabular}

Tabla 4: Resultados de la subescala de «alegría» de los SP

Estas cuatro tablas corresponden a las variaciones que han experimentado los SP, comparando los datos obtenidos en la EVEA que se les ha entregado antes de comenzar la traducción (pre) y la copia que han cumplimentado una vez acabada la traducción (post) de cada subescala. Como se puede apreciar, las variaciones en el SP1 y en el SP2 son elevadas en las cuatro subescalas. En estos dos sujetos aumentan notablemente los niveles de «tristeza», de «ansiedad» y de «ira-hostilidad» y disminuye el nivel de «alegría». Sin embargo, en el SP3, los niveles de «tristeza», de «ansiedad»y de «ira» han disminuido en comparación con los niveles iniciales que experimentaba el sujeto, mientras que el nivel de «alegría» ha aumentado considerablemente.

Atendiendo a los datos obtenidos mediante la escala EVEA de los sujetos profesionales, se puede apreciar que los diferentes estados de ánimo han sufrido alteraciones, como se puede apreciar en la gráfica que se muestra a continuación: 


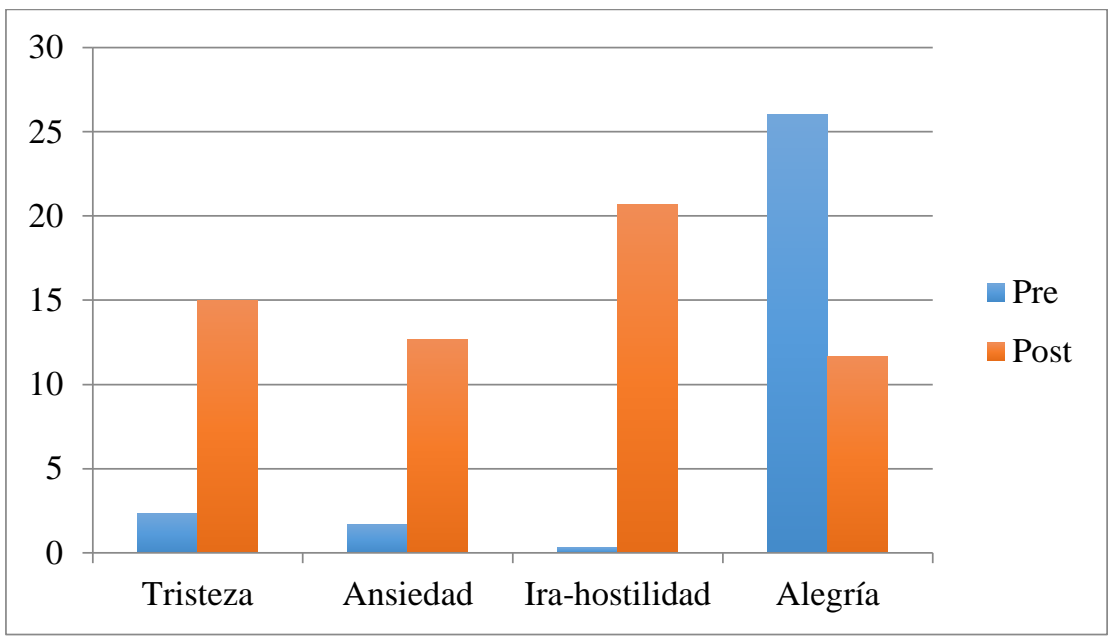

Gráfica 1: Comparación de medias obtenidas pre-test y post-test de los SP

Por otra parte, al final de la sesión, preguntamos a los sujetos si había algún adjetivo que no apareciera en la escala EVEA pero que definiese su estado de ánimo al acabar la traducción. Únicamente el SP1 quiso incluir el adjetivo «molesto» para describir su estado de ánimo.

\subsubsection{Datos cualitativos (TAPS)}

Los datos obtenidos mediante la escala EVEA permiten comparar los estados de ánimo iniciales y finales de los sujetos, pero, con la finalidad de comprobar cómo se sienten los sujetos durante el proceso traductor, se han utilizado los TAPs. Además, así hemos podido comprobar si existe una relación entre los resultados cuantitativos y cualitativos del estudio. Debido a que la recogida de las verbalizaciones de las sesiones de aproximadamente una hora de duración de cada uno de los sujetos sobrepasaría la extensión de este tipo de investigación, hemos realizado una recopilación de algunas de sus verbalizaciones, en relación con sus emociones y estados de ánimo, descartando así, los comentarios que aludían al procedimiento, a las herramientas utilizadas, a la toma de decisiones de carácter lingüístico, etc.

En relación con los SP, tanto el SP1 como el SP2 mientras traducían, resaltaban las sensaciones negativas que les producía el texto, realizando comentarios del tipo:

- «Tengo que tener fuerza interior para contar esta historia» (SP1)

- «Tengo un nudo en la garganta» (SP1)

- «Se me remueve el estómago, iqué triste!» (SP1) 
- «Me está afectando, me está costando mantener las ganas de llorar» (SP2)

- «No verbalizo mucho porque me cuesta, me he puesto a la defensiva al ver el texto y me he cerrado porque no quiero que me afecte, y al hablar en voz alta siento que es más real» (SP2)

Estos dos sujetos también realizaron comentarios en los que criticaron la situación política de Venezuela, llegando a mostrar agresividad y enfado, pronunciando incluso palabras mal sonantes mientras traducían. Además, algunos destacaron el impacto negativo que les producían las imágenes, comentando que preferían eliminar las fotografías porque «ile estaban revolviendo el estómago!» (SP1).

Sin embargo, las verbalizaciones que realizó el SP3 tenían distinto enfoque, al igual que los datos obtenidos mediante la escala EVEA de este sujeto en particular. Mediante las verbalizaciones, se puede comprobar que se sentía mucho más cómodo verbalizando, ponía música, tarareaba, respondía a correos electrónicos, miraba el móvil mientras traducía y mostró un estado de tranquilidad durante toda la sesión.

En resumen, los tres SP concluyeron afirmando que era difícil mantener la objetividad en este tipo de situaciones, pero que el sentido de la profesionalidad era lo que les impulsaba a controlar sus emociones. EI SP2 comentó que: «obviamente, somos seres humanos, es normal que esto nos afecte. Cuesta mantener la objetividad, la calma y la tranquilidad al enfrentarnos a este tipo de textos; pero el sentido de la profesionalidad me impulsa a continuar. Necesitan mi trabajo para que la historia se conozca» (SP2).

\subsection{Sujetos no profesionales $(S n P)$}

\subsubsection{Datos cuantitativos (EVEA)}

A continuación, expondremos los datos cuantitativos obtenidos de los sujetos no profesionales (SnP). Al igual que en el caso de los SP, analizaremos los resultados por subescalas, obteniendo una puntuación de 0 a 40.

\begin{tabular}{|l|l|l|l|l|l|}
\hline \multicolumn{2}{|c|}{ SNP1 } & \multicolumn{2}{c|}{ SNP2 } & \multicolumn{2}{c|}{ SNP3 } \\
\hline PRE & POST & PRE & POST & PRE & POST \\
\hline 7 & 30 & 8 & 22 & 5 & 27 \\
\hline
\end{tabular}

Tabla 5: Resultados de la subescala de «tristeza-depresión» de los SnP 


\begin{tabular}{|l|l|l|l|l|l|}
\hline \multicolumn{2}{|c|}{ SNP1 } & \multicolumn{2}{c|}{ SNP2 } & \multicolumn{2}{c|}{ SNP3 } \\
\hline PRE & POST & PRE & POST & PRE & POST \\
\hline 20 & 9 & 11 & 19 & 27 & 35 \\
\hline
\end{tabular}

Tabla 6: Resultados de la subescala de «ansiedad» de los SnP

\begin{tabular}{|l|l|l|l|l|l|}
\hline \multicolumn{2}{|c|}{ SNP1 } & \multicolumn{2}{c|}{ SNP2 } & \multicolumn{2}{c|}{ SNP3 } \\
\hline PRE & POST & PRE & POST & PRE & POST \\
\hline 2 & 28 & 18 & 16 & 3 & 35 \\
\hline
\end{tabular}

Tabla 7: Resultados de la subescala «ira-hostilidad» de los SnP

\begin{tabular}{|l|l|l|l|l|l|}
\hline \multicolumn{2}{|c|}{ SNP1 } & \multicolumn{2}{c|}{ SNP2 } & \multicolumn{2}{c|}{ SNP3 } \\
\hline PRE & POST & PRE & POST & PRE & POST \\
\hline 29 & 9 & 24 & 8 & 24 & 5 \\
\hline
\end{tabular}

Tabla 8: Resultados de la subescala de «alegría» de los SnP

Como se puede apreciar de los datos cuantitativos expuestos en las tablas anteriores, todos los sujetos experimentan alteraciones psicológicas significativas (gráfica 2) sobre las medias obtenidas antes y después de la evaluación de los tres SnP: 


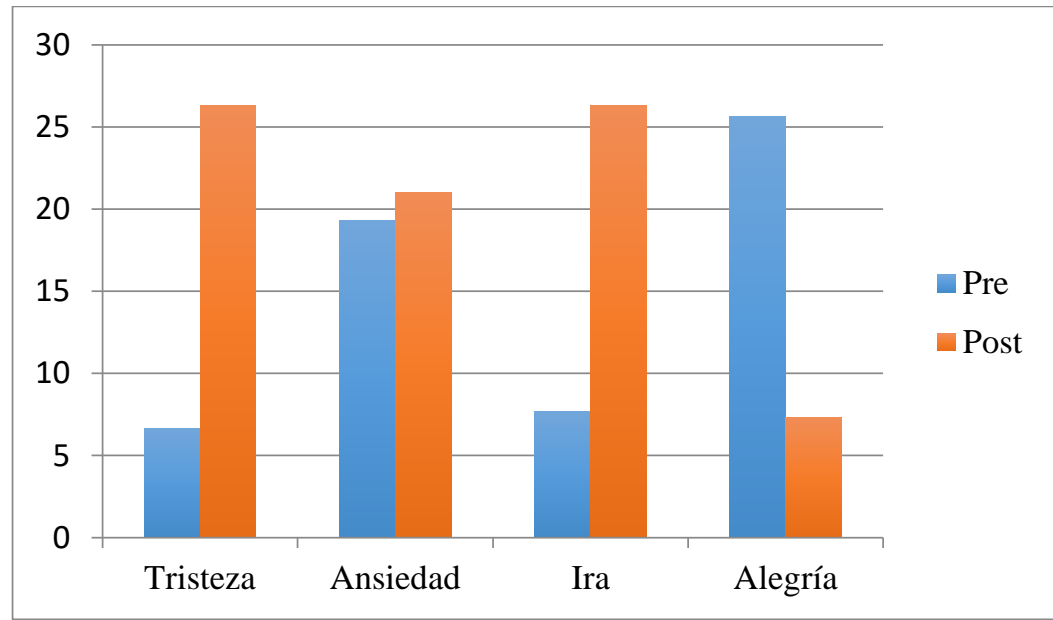

Gráfica 2: Comparación de medias obtenidas pre-post de los SnP

Además, al preguntarles a los sujetos al final de cada sesión si existe algún adjetivo que no aparezca en la escala EVEA pero que describa sus estados de ánimo, al acabar la traducción, el SnP1 añade las palabras «pena» $y$ «dolor», y el SnP3 añade las palabras «rabia» y «coraje».

\subsubsection{Datos cualitativos (TAPs)}

A la hora de verbalizar, los SnP se expresaron mucho menos que los SP. Sin embargo, todos dejaron constancia de la manera en la que el texto les afectó a sus emociones, con oraciones como:

- «iQué rabia!» (SnP1).

- «No sé cómo explicar lo que siento, por eso no verbalizo, venía tranquila y ahora estoy alterada» (SnP1).

- «Me estoy emocionando, iqué duro!» (SnP1).

- «Las imágenes me acaban de romper el alma» (SnP1).

- «Madre mía, ¿las fotos son reales?» (SnP2).

- «Me siento rara» (SnP2).

- «Antes de empezar estaba feliz, me suele pasar cuando veo cosas injustas» (SnP3).

- «Es muy incómodo traducir este tipo de textos» (SnP3).

- «Tengo que concentrarme, esto es muy fuerte» (SnP3).

Por otra parte, otro aspecto importante son los comentarios que realizaron los tres sujetos no profesionales en relación con la falta de preparación que tenían para traducir este tipo de textos: 
- «Esta traducción me ha servido para darme cuenta de la realidad a la que nos enfrentamos los traductores e intérpretes, y lo poco preparados que estamos para traducir estos textos» (SnP1).

- «Tenemos formación lingüística, pero creo que no nos forman para esto, y podemos encontrar textos con complejidad a nivel emocional en casi todas las especializaciones» (SnP2).

- "Yo no sé cómo reaccionaría si me llegan encargos de este tipo» (SnP3).

A pesar de que el objetivo principal de este trabajo no era valorar la calidad de las traducciones ni la manera en la que se expresan las emociones, cabe destacar que, en el caso de los SnP, la calidad de las traducciones era bastante baja, llegando incluso a omitir las partes con mayor carga emocional, realizar cambios de sentidos relevantes para el entendimiento del texto, faltas ortográficas o dejar frases sin acabar. Aunque no corresponde a este estudio analizar el motivo de este tipo de errores, nos ha parecido relevante destacarlo, ya que se trata de alumnos de $4^{\circ}$ curso del grado en Traducción e Interpretación, y por lo tanto, cometer este tipo de errores podría estar relacionado con los estados de ánimos negativos que experimentan los SnP debido a la escasa preparación sobre este tipo de textos con carga emocional negativa.

\subsection{Evaluación de los datos cuantitativos}

Tras analizar los datos obtenidos mediante los dos métodos empleados y las comparaciones entre las medias de los dos grupos, nos parece relevante observar las variaciones globales, es decir, las medias obtenidas conjuntamente de los 6 sujetos para cada subescala, con la finalidad de analizar si el texto ha afectado a los estados de ánimo de los traductores, independientemente de si se trata de sujetos profesionales o no.

\begin{tabular}{|c|c|c|}
\hline \multirow{2}{*}{ Emoción } & Tipo & Media \\
\hline \multirow{2}{*}{ Tristeza } & pre & 4,5000 \\
\cline { 2 - 3 } & post & 20,6667 \\
\hline \multirow{2}{*}{ Ansiedad } & pre & 10,5000 \\
\hline & post & 16,8333 \\
\hline
\end{tabular}

Hikma 20 (1) (2021), 185 - 219 


\begin{tabular}{|c|c|c|}
\hline Ira & post & 23,5000 \\
\hline \multirow{2}{*}{ Alegría } & pre & 25,8333 \\
\cline { 2 - 3 } & post & 9,5000 \\
\hline
\end{tabular}

Tabla 10: Medias totales de todos los sujetos

En esta tabla, se puede apreciar que las variaciones globales de todos los sujetos conjuntamente son elevadas y, por lo tanto, refleja la manera en la que los textos emotivos afectan a las emociones de los traductores. Concretamente, la «tristeza» ha aumentado alrededor de 16 puntos, la «ansiedad» en torno a 6 puntos, la «ira» casi 20 puntos y la «alegría» ha disminuido 16 puntos. Por lo tanto, los cuatro estados de ánimo han experimentado alteraciones tras la traducción del texto, como se muestra en la siguiente gráfica:

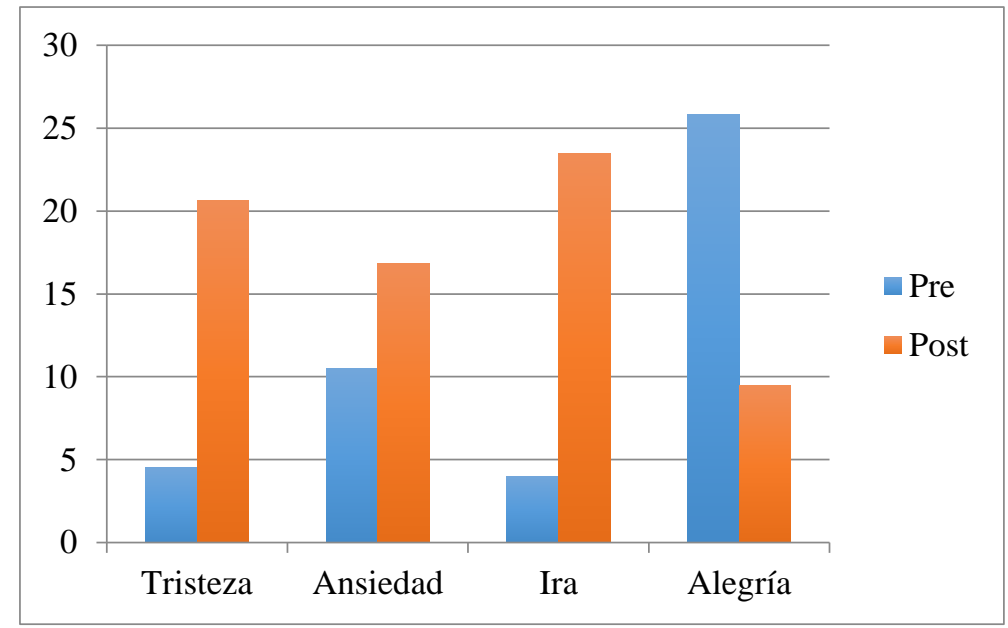

Gráfica 7: Medias totales de todos los sujetos

En definitiva, nos gustaría concluir afirmando que los datos inter e intragrupales analizados anteriormente, así como las medias globales de los seis sujetos, dejan constancia de que, en todos los casos, los estados de ánimo de los sujetos han experimentado cambios, incrementándose los niveles finales en las emociones negativas y disminuyéndose en el caso de las positivas. 


\subsection{Comparación de los datos cualitativos de ambos grupos}

Una vez analizados los datos obtenidos mediante los dos métodos empleados de los dos grupos por separado, comparemos los datos cualitativos obtenidos. Así, podremos establecer posibles patrones comunes entre estos, además de las principales diferencias o semejanzas encontradas en la manera en la que las emociones de traductores profesionales y no profesionales se ven alteradas mientras traducen textos emotivos.

En primer lugar, cabe destacar que los resultados obtenidos de la escala EVEA no son estadísticamente significativos $(p>0,05)$, debido principalmente a la escasez de la muestra. Sin embargo, hemos podido observar que las medias obtenidas de los grupos varían en cada subescala, como se muestra a continuación:

\begin{tabular}{|c|c|c|c|}
\hline \multirow{2}{*}{} & Media & Desviación estándar \\
\hline \multirow{2}{*}{ Tristeza pre } & Profesional & 2,3333 & 4,04145 \\
\cline { 2 - 4 } & No profesional & 6,6667 & 1,52753 \\
\hline Tristeza post & Profesional & 15,0000 & 12,52996 \\
\cline { 2 - 4 } & No profesional & 26,3333 & 4,04145 \\
\hline Ansiedad pre & Profesional & 1,6667 & 2,08167 \\
\cline { 2 - 4 } & No profesional & 19,3333 & 8,02081 \\
\hline Ansiedad post & Profesional & 12,6667 & 12,50333 \\
\cline { 2 - 4 } & No profesional & 21,0000 & 13,11488 \\
\hline \multirow{2}{*}{ Ira pre } & Profesional & 0,3333 & 0,57735 \\
\cline { 2 - 4 } & No profesional & 7,6667 & 8,96289 \\
\hline Ira post & Profesional & 20,6667 & 18,33939 \\
\cline { 2 - 4 } & No profesional & 26,3333 & 9,60902 \\
\hline Alegría pre & Profesional & 26,0000 & 10,39230 \\
\cline { 2 - 4 } & No profesional & 25,6667 & 2,88675 \\
\hline
\end{tabular}

Hikma 20 (1) (2021), 185 - 219 


\begin{tabular}{|c|c|c|c|}
\hline Alegría post & Profesional & 11,6667 & 11,06044 \\
\cline { 2 - 4 } & No profesional & 7,3333 & 2,08167 \\
\hline
\end{tabular}

Tabla 9: Resultados totales obtenidos en la EVEA

Esta tabla recoge tanto las medias de los SnP como de los SP para cada subescala antes y después de realizar la traducción. Como se puede apreciar, en ambos grupos existen variaciones en los estados de ánimo. A continuación, mostraremos dichas medias a modo de gráficas de cada subescala por separado, con la finalidad de comparar visualmente las variaciones de cada estado anímico.

4.4.1. Subescala «tristeza-depresión»

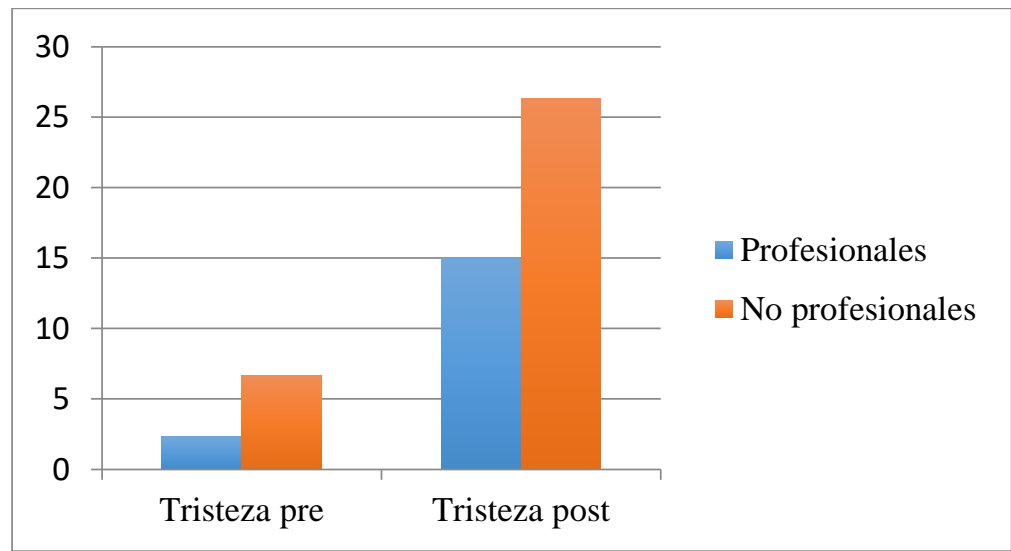

Gráfica 3: Comparación de los niveles pre y post de ambos grupos en la subescala de «tristeza-depresión»

En relación con la subescala de la EVEA de «tristeza-depresión» observamos que en ambos grupos ha aumentado considerablemente el nivel de «tristeza». Además, en los SnP este aumento es aún mayor, elevándose casi 20 puntos el grado de «tristeza», mientras que en los SP ha aumentado alrededor de 13 puntos. 


\subsubsection{Subescala «ansiedad»}

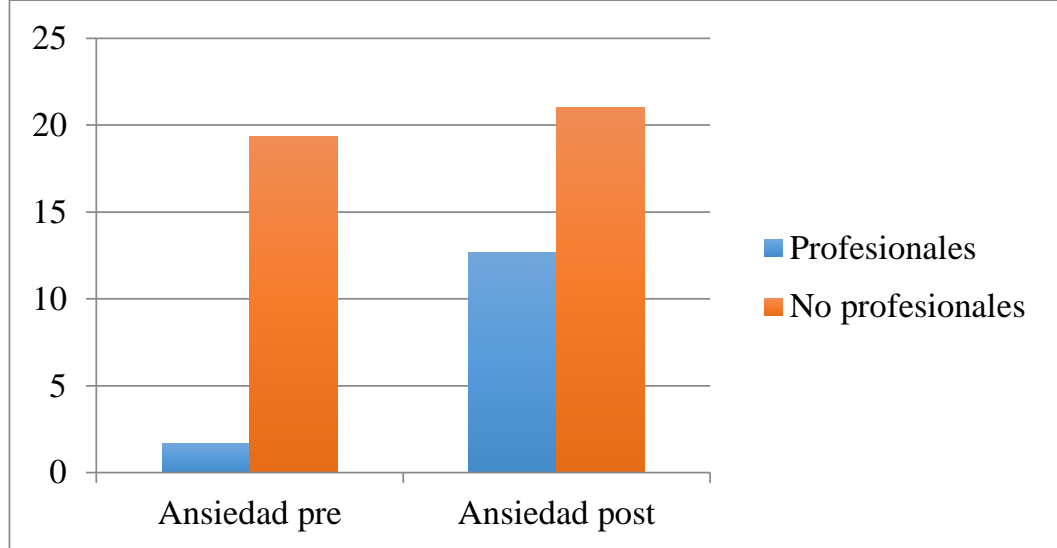

Gráfica 4: Comparación de los niveles pre y post de ambos grupos en la subescala de «ansiedad»

En relación con la subescala de «ansiedad» se observa que en los dos grupos el nivel ha aumentado. Los SnP finalizan la traducción con un grado de ansiedad notablemente mayor que los SP. Sin embargo, la variación que experimentan los $\mathrm{SnP}$ es menor, ya que comienzan la sesión con un nivel de ansiedad bastante elevado, aumentando únicamente dos puntos al finalizar la prueba. En cambio, en el caso de los SP, el nivel de ansiedad final es menor, pero la variación es mayor, aumentando alrededor de 10 puntos.

4.4.3. Subescala «ira-hostilidad»

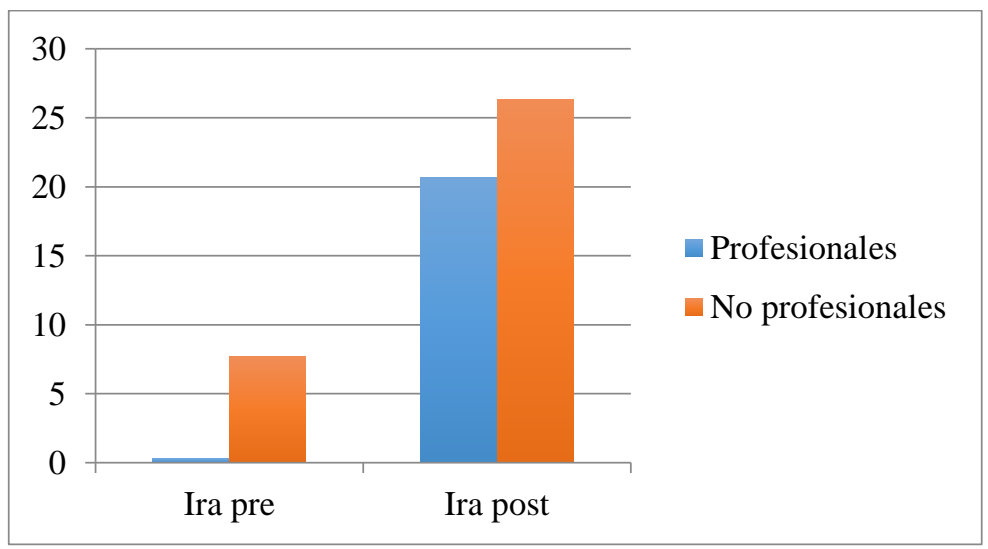

Hikma 20 (1) (2021), 185 - 219 


\section{Gráfica 5: Comparación de los niveles pre y post de ambos grupos en la subescala de «ira-hostilidad»}

En cuanto a la subescala de «ira-hostilidad», al igual que en las subescalas anteriores, se puede apreciar que en ambos grupos los niveles de ira han aumentado considerablemente. A pesar de que el nivel de ira de los SnP es mayor al finalizar la traducción, si lo comparamos con los niveles iniciales, las variaciones en ambos grupos son parecidas, siendo incluso mayor en los SP, ya que en este grupo aumenta alrededor de 20 puntos y en los SnP 18 puntos.

\subsubsection{Subescala «alegría»}

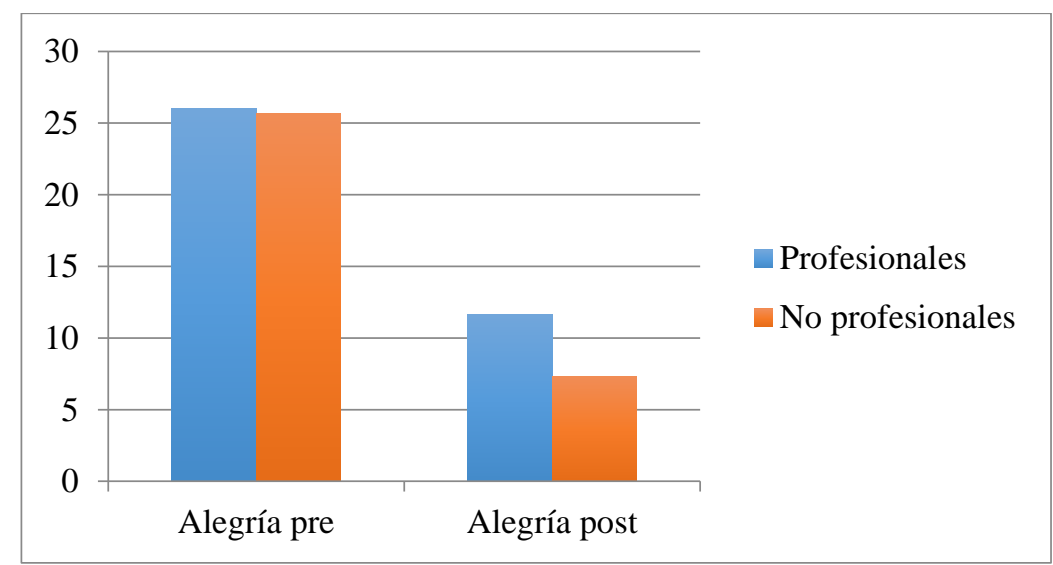

Gráfica 6. Comparación de los niveles pre y post de ambos grupos en la subescala de «alegría»

En el caso de la subescala de «alegría», ambos grupos han comenzado la sesión con un nivel similar y al acabar la traducción ese nivel ha disminuido. En el caso de los SnP, esa disminución es mayor (alrededor de 18 puntos), mientras que en los SP ha disminuido en torno a 14 puntos.

\section{CONCLUSIONES}

Atendiendo a las emociones que experimentaron los sujetos durante la realización de la traducción, gracias al uso de los TAPs, se ha observado que los tres SP no han reaccionado del mismo modo, como se esperaba. Por una parte, dos de los SP han dejado constancia de que su estado de ánimo se ha visto alterado por el contenido del texto mientras traducían, y que, a pesar de llevar una larga trayectoria como traductores profesionales, el texto les afectó anímicamente. Por otra parte, el último SP ha reflejado lo contrario durante el transcurso de la traducción, mostrando una actitud de calma y tranquilidad y 
demostrando mediante sus verbalizaciones que no prestaba atención a la emotividad del texto, realizando comentarios sobre aspectos que no estaban relacionados con la traducción. Esto refleja que, a priori, no existe un patrón común en la manera en la que los SP se enfrentan a traducciones con carga emotiva y que la profesionalidad puede no estar estrictamente relacionada con la gestión de las emociones en este tipo de textos, dejando la vía libre a otros factores como la inteligencia emocional, las diferencias individuales, la relación con el tema o la situación personal de cada individuo. No obstante, en el caso de los traductores no profesionales, y teniendo en cuenta que los tres sujetos afirmaron que no se sentían cómodos verbalizando y, por consiguiente, la riqueza informativa de sus verbalizaciones era mucho menor que la de los sujetos profesionales, los tres sujetos dejaron constancia de las dificultades a nivel emocional que les provocó el texto y, además, destacaron la escasa preparación que tenían para realizar este tipo de traducciones.

Los resultados obtenidos de la EVEA muestran que los SnP obtuvieron una puntuación más alta al finalizar la traducción en las subescalas de «tristeza-depresión», «ansiedad» e «ira-hostilidad» que los SP. Por lo tanto, los SnP sintieron más tristeza, más ira y más ansiedad que los SP al finalizar la traducción. Sin embargo, si tomamos en cuenta los niveles iniciales que presentaban los sujetos, las variaciones en sus estados de ánimo no eran tan diferentes entre los dos grupos. Así pues, en la subescala de «ansiedad", en los SP, el nivel de ansiedad aumentó 11 puntos, mientras que en los SnP aumentó únicamente alrededor de 2 puntos, ya que comenzaron la traducción con un nivel de ansiedad elevado. En la subescala de «ira-hostilidad», la variación en los niveles de ira de los SP era ligeramente mayor que en los $\mathrm{SnP}$, aunque estos últimos hayan presentado al final un nivel mayor en esta subescala. Sin embargo, en la subescala de «tristeza», tanto el nivel final como la variación experimentada era considerablemente mayor en el grupo de SnP. Mediante estos datos, se ha podido constatar que, al finalizar la traducción en todos los sujetos, tanto en los SP como en los SnP, las emociones negativas han incrementado y las positivas han disminuido. Por lo tanto, se puede concluir afirmando que en mayor o en menor medida los textos emotivos afectan a los traductores y que no existen diferencias considerables entre traductores profesionales y no profesionales.

Por último, la metodología empleada en esta investigación ha permitido obtener datos suficientes para cumplir con los objetivos preestablecidos. Los TAPs han permitido observar tanto las emociones que experimentaron los sujetos durante la realización de la traducción como la manera en la que los sujetos gestionaron esas emociones, para que no afectaran la calidad de la traducción. Por otra parte, la escala EVEA ha permitido observar cómo han cambiado las emociones de los traductores antes y después de traducir un texto con carga emotiva. Por lo tanto, la combinación de ambos métodos ha 
permitido analizar las emociones experimentadas antes, durante y después de traducir un texto de carga emocional negativa y comparar cómo se enfrentan a la traducción de este tipo de textos los traductores profesionales y los no profesionales. Cabe destacar que la mayor parte de los datos analizados han sido los obtenidos mediante la EVEA, ya que consideramos que ha proporcionado datos muy relevantes acerca de los cambios en los estados de ánimo de los sujetos y, además, al tratarse de una prueba psicométrica validada, los datos cualitativos obtenidos se consideran fiables.

En cuanto a los TAPs, consideramos que ha sido una herramienta útil teniendo en cuenta que el objetivo era acceder únicamente a los pensamientos relacionados con los estados de ánimo de los traductores, descartando así para el análisis las verbalizaciones que no estuvieran asociadas a las emociones, pero podría no considerarse útil cuando se pretende acceder a procesos cognitivos más generales o automatizados.

\section{REFERENCIAS BIBLIOGRÁFICAS}

Alves, F. (1996). Veio-me um 'click' na cabeça: The Theoretical Foundations and the Design of a Psycholinguistically Oriented, Empirical Investigation on German-Portuguese Translation Processes. Méta, 41(1), 33-44.

Anderson, J. (2005). The double agent: aspects of literary translator affect as revealed in fictional work by translators. Linguistica Antverpiensa, New Series-Themes in Translation, 4,171-182.

Arjona Arcas, J. F. (2002). Evaluación subjetiva y respuestas psicofisiológicas en la inducción de estados de ánimo ante procedimientos audiovisuales (Tesis doctoral). Facultad de Psicología, Universidad de Málaga.

Asadi, P. y Séguinot, C. (2005). Shortcuts, Strategies and General Patterns in a Process Study of Nine Professionals. Meta: Translators' Journal, 50(2), 522-547.

Ávila Espada, A. y Giménez de la Peña, A. (1991). Los adjetivos en tareas de evaluación psicológica: Propiedades y valor estimular. Revista de psicología general y aplicada: Revista de la Federación Española de Asociaciones de Psicología, 44(4), 465-475. Recuperado de http://bit.ly/31CY2dT

Baistow, K. (2000). The Emotional and Psychological Impact of Community Interpreting. Londres: Babelea.

Basile, E. (2005). Responding to the Enigmatic Address of the Other: A Psychoanalytic Approach to the Translator's Labour. New Voices in Translation Studies, 1, 12-30. Recuperado de http://bit.ly/2MM5bp1 
Bell, R. T. (1998). Psycholinguistic/cognitive approaches. En M. Baker (Ed.), Routledge Enclycopedia of Translation Studies (pp. 185-190). Londres: Routledge.

Blair, D. T. y Ramones V. A. (1996). Understanding vicarious traumatization. Journal of psychosocial nursing and mental health services, 34(11), 24-30.

Bolaños Medina, A. (2012). Las pruebas psicométricas en la investigación empírica sobre los procesos cognitivos del traductor. En S. Cruces Collado, A. Luna Alonso, M. Del Pozo Triviño y A. Álvarez Lugrís (Eds.). Traducir en la Frontera. Actas del IV Congreso de AIETI 469-482. Granada: Atrio. Recuperado de http://bit.ly/2F8vEXr

- (2014). La investigación de las diferencias individuales en traductología cognitiva. Trans, Revista de Traductología, 18, 199-214. Recuperado de http://bit.ly/2WIS2S1

- (2015). Apuntes para una psicología social de la traducción. Nuevos horizontes en los Estudios de Traducción e Interpretación, 151-153. Recuperado de http://bit.ly/2XKiTtk

- (2016). Translation Psychology within the Framework of Translator Studies: New Research Perspectives and Pedagogical Implications. En C. Martín de León y V. González-Ruiz (Eds.). From the Lab to the Classroom and Back Again (pp. 60-99). Suiza: Peter Lang.

Bush, P. (2012). Toil, Trouble and Jouissance. En R. Wilson y L. Gerber (Eds). Creative Constraints: Translation and Authorship (pp. 119-131). Clayton, VIC: Monash University Publishing.

Clark, M.; Gioro, S. (1998). Nurses, Indirect Trauma and Prevention, Image: Journal of Nursing Scholarship, 30(1),85-87.

Davou, B. (2007). Interaction of emotion and cognition in the processing of textual material. Meta: Translators' Journal, 52(1), 37-47.

Ericsson, K. A. y Simon, H. A. (1980). Verbal Reports as Data. Psychological Review, 87(3), 215-251.

Ericsson, K. A. y Simon, H. A. (1993). Protocol Analysis. Verbal Reports as Data. Cambridge, Massachusetts: The MIT Press.

Fraser, J. (1993). Public accounts: using verbal protocols to investigate community translation. Applied Linguistics, 14(4), 325-343.

Goleman, D. (1995). Emotional Intelligence. Nueva York: Batam Books. 
Gotlib, I. H. y Cane, D. B. (1989). Self-report assessment of depression and anxiety. En P.C. Kendall y D. Watson (Eds.) Personality, psychopathology, and psychotherapy. Anxiety and depression: Distinctive and overlapping features (pp. 131-169). San Diego: Academic Press.

Hansen, G. (1999). Probing the process in translation: methods and results. Frederiksberg: Samfundslitteratur.

- (2005). Experience and Emotion in Empirical Translation Research with Think-Aloud and Retrospection. Meta: Translators Journal, 50(2), 511521.

Hervas, G. y Vazquez, C. (2013). Low spirits keep rewards subdued: Decreases in sensitivity to reward and vulnerability to dysphoria. Behavior Therapy, 44(1), 62-74.

Holmes, J. S. (1988). The Name and Nature of Translation Studies. Translated: Papers on Literary Translation and Translation Studies, 6780. Amsterdam/Philadelphia: Rodopi.

Hubscher-Davidson, S. (2007). An Empirical Investigation into the Effects of Personality on the Performance of French to English Student Translators (Tesis doctoral). University of Bath, Inglaterra.

- (2013). Emotional Intelligence and Translation Studies: A New Bridge. Meta: Translator's Journal, 58(2), 324-346.

- (2018). Translation and Emotion: A Psychological Perspective. Nueva York: Routledge.

Hurtado Albir, A. (2011). Traducción y traductología. Madrid: Cátedra.

Jääskeläinen, R. H. (1998). Think-aloud protocols. En M. Baker (Ed.) Enciclopedia of Translation Studies, 265-269. Londres: Routledge.

- (2012). Translation Psychology. En Gambier, Y. y L. van Doorslaer (Eds.) Handbook of Translation Studies, 3 (pp. 191-197). Amsterdam/Philadelphia: John Benjamins.

Jensen, A. (1999). Time pressure in translation. En Hansen, G. (Ed.). Probing the process in translation: methods and results. Copenhagen Studies in Language, 24 (pp. 103-119).

Krings, H. P. (1986). Was in den Köpfen von Übersetzernvorgeht: Eineempirische Untersuchung zur Struktur des Übersetzungsprozessesan Fortgeschrittenen. Tubinga: Gunter Narr. 
Kussmaul, P. (1995). Training the translator. Amsterdam: John Benjamins.

Ladmiral, J. R. (1996). Pour une psychologie de la traduction. Übersetzungswissenschaftim Umbruch. Festschrift Für-Wolfram Wilss, 27-35. Hillsdale, NJ: Lawrence Erlbaum.

Lam, L. T. y Kirby, S. L. (2002). Is Emotional Intelligence an Advantage? An Exploration of the Impact of Emotional and General Intelligence on Individual Performance. The journal of social Psychology, 142(1), 133143. Recuperado de http://bit.ly/2MW6DoG

Lehr, C. (2013). Influences of Emotion on Cognitive Processing in Translation: A Framework and Some Empirical Evidence. International Online Workshop on Affective Factors in Translation Process Research: To Feel or Not to Feel? That is the Question. Aston University.

Lorenzo, M. P. (1999). Apuntes para una discusión sobre métodos de estudio del proceso de traducción. En G. Hansen (Ed.). Probing the process in translation: Methods and results. Copenhagen studies in language, 24 (pp. 21-42). Frederiksberg: Samfundslitteratur.

Lörscher, W. (1991). Translation Performance, Translation Process, and Translation Strategies. A Psycholinguistic Investigation. Tubinga: Gunter Narr Verlag.

Loutan, L., Farinelli, T. y Pampallona, S. (1999). Medical interpreters have feelings too. Sozial und Präventivmedizin, 44(6), 280-282.

Lubin, B. (1965). Adjective check lists for measurement of depression. Archives of General Psychiatry, 12, 57-62.

Moreno Rosset, C. (2005). Evaluación psicológica: concepto, proceso y aplicación en las áreas del desarrollo y de la inteligencia. Madrid: Sanz y Torres.

Murphy, K.R. (2006). A critic of emotional intelligence: What are the problems and how can they be fixed. Nueva Jersey: Lawrence Erlbaum Association.

Neunzig, W. (2001). La intervención pedagógica en la enseñanza de la traducción on-line. Cuestiones de método y estudio empírico (Tesis doctoral). Universidad Autónoma de Barcelona, España.

Orozco Jutorán, M. (2002). Revisión de investigaciones empíricas en traducción escrita. TRANS. Revista de Traductología, 6, 63-85. 
Pacheco-Unguetti, A. P., Acosta, A., Marqués, E. y Lupiáñez, J. (2011). Alterations of the attentional networks in patients with anxiety disorders. Journal of Anxiety Disorders, 25, 888-895.

Pahlavani, P. y Asroush M. H. (2013). The Relationship between Emotional Intelligence (EQ) and the EFL. The Iranian EFL Journal, 9(5), 39-50.

Pino-Sedeño, T., Peñate, W. y Bethencourt, J. M. (2010). La escala de valoración del estado de ánimo (EVEA): análisis de la estructura factorial y de la capacidad para detectar cambios en estados de ánimo. Análisis y Modificación de Conducta, 36(153), 19-32. Recuperado de http://bit.ly/2ZreAn9

Presas, M. (1996). Problemes de traducció i competència traductora. Bases per a una pedagogia de la traducción (Tesis Doctoral). Universitat Autònoma de Barcelona, España.

Provencio Ortega, M. (2012). Patrones de escaneo visual ante expresiones faciales negativas en personas con creencias persecutorias (Tesis doctoral). Universidad Complutense de Madrid, España.

Pueyo, A. A. (1993). Evaluación del estado de ánimo y de la activación: Estado de la cuestión. En M. Forms y M. T. Anguera (Eds.), Aportaciones recientes a la evaluación psicológica (pp. 283-306). Barcelona: PPU.

Rabadán Álvarez, R. (1992). Tendencias teóricas en los estudios contemporáneos de traducción. En P. Fernández Nistal (Ed.) Estudios de traducción, ICE Universidad de Valladolid, 45-59.

Reiss, K. (2000). Translation Criticism. Manchester: St. Jerome Publishing.

Rodrigues, C. (2002). A Abordagem Processual no Estudos da Tradução: uma meta-análise cualitativa. Cadernos de tradução, $X$, 23-57. Recuperado de http://bit.ly/2lcq3kJ

Rojo López, A.M. (2015). Translation Meets Cognitive Science: The Imprint of Translation on Cognitive Processing. Multilingua, 34(6), 721-746. Recuperado de http://bit.ly/2MKodfm

Rojo López, A. M. y Ramos Caro, M. (2016). Can Emotion Stir Translation Skills? En R. Muñoz Martín (Ed.). Reembedding Translation Process Research, 107-130. Amsterdam y Philadelphia: Jonh Benjamins.

Romero Martín, N. (2012). Memoria auto-referente y autobiográfica en la depresión mayor: factores de vulnerabilidad implicados (Tesis doctoral). Universidad Complutense de Madrid, España. 
Saldanha, G. y O'Brien, S. (2013). Research Methodologies in Translation Studies. Londres y Nueva York: Routledge.

Sánchez-Elvira Paniagua, A. y Olmedo Montes, M. (2003). Marco conceptual de la psicología de las diferencias individuales. En A. Sánchez-Elvira Paniagua (Ed.), Introducción al estudio de las diferencias individuales (pp. 103-144). Madrid: Sanz y Torres.

Sandrock, U. (1982). Thinking Aloud Protocols (TAPS), Ein Instrument zur Dekomposition des komplexen Prozesses «Übersetzen» (Tesis doctoral). Universidad de Kassel, Alemania.

Sanz, J. (1994). ¿Existen los autoesquemas depresivos y ansiosos? Boletín de Psicología, 43, 53-88.

- (2001). Un instrumento para evaluar la eficacia de los procedimientos de inducción de estado de ánimo: La Escala de Valoración del Estado de Ánimo (EVEA). Análisis y Modificación de Conducta, 27, 71-110. Recuperado de http://bit.ly/2KjDeme

- y Dobson, K. S. (1994). Induced depressed mood, selective attention and automatic vigilance. Informe de investigación. Facultad de Psicología. Universidad Complutense de Madrid.

—., Gutiérrez, S. y García-Vera, M. P. (2013). Propiedades psicométricas de la Escala de Valoración del Estado de Ánimo (EVEA): una revisión. Ansiedad y estrés, 20(1).

Schutte, N. S. (2001). Emotional Intelligence and Task Performance. Imagination, Cognition, and Personality, 20(4),114-135.

Soto Almela, J. (2015). Una aproximación a los estudios empíricos en Traductología: diseños y herramientas. InTRAlinea Online Translation Journal, 17, 1-12. Recuperado de http://bit.ly/2YOwEo0

Spielberger, C. D., Gorsuch, R. L. y Lushene, R. E. (1970). Manual for the State-Trait Anxiety Inventory. Adaptación española, $3^{\underline{a}}$ ed. Madrid: TEA.

Spielberger, C. D., Jacobs, G., Russel, S. y Crane, R. S. (1983). Assessment of anger: The State-Trair Anger Scale. En J. N. Butcher y C. D. Spierlberg (Eds), Advances in personality assessment, 2 (pp. 159-187). Hillsdale, NJ: LEA.

Spranger, E. (1920). Lebensformen: Geisteswissenschaftliche Psychologie und Ethik der Persönlichkeit. Halle: M. Niemeyer.

Valero-Garcés, C. (2006). El impacto psicológico y emocional en los intérpretes y traductores de los servicios públicos: un factor a tener en 
cuenta. Quaderns: revista de traducció, 13, 141-154. Recuperado de http://bit.ly/2XXIcZc

Varzande, M.; Jadidi, E. (2015). The Effect of Translators' Emotional Intelligence on Their Translation Quality. English Language Teaching, 8(8), 104-111. Recuperado de http://bit.ly/31JMw0e

Wolf, M. y Fukari, A. (2007). Constructing a Sociology of Translation. Amsterdam: John Benjamins. 